\title{
Socio-Linguistic Study of Meaning Extension in Communication among Male Youths in Northern Nigeria
}

\author{
Bello Ibrahim \\ Al-Qalam University Katsina-Nigeria \\ bello.ibrahim@auk.edu.ng,belloktn@gmail.com \\ Rilwan Yusuf Jibo \\ jibojr69@gmail.com \\ Hamisu Hamisu Haruna \\ Al-Qalam University Katsina-Nigeria \\ hhhamisu@gmail.com
}

DOI: http://doi.org/ 10.36892/ijlls.v2i4.335

\begin{tabular}{ll}
$\begin{array}{l}\text { Received: } \\
\text { 04/09/2020 }\end{array}$ & The paper examines meaning extension in communication among male \\
Accepted: & youths in some northern states such as Katsina, Kano, Kaduna and \\
06/12/2020 & Zamfara. The variables under study comprise of words, phrases and \\
& sentences in English and Hausa languages. The paper also examines \\
& the expressions, literal and contextual meanings and how they are used \\
\hline Keywords: & among the educated and uneducated (western education) youths. The \\
words, & data gathered by the researchers through observation are twenty five \\
Phrases, & (25) samples, and were further presented and analysed using \\
Sentences, & descriptive method. The findings revealed that the youths use the \\
meaning. & expressions in a conversation to make it socially decorated and show \\
& fancy in conversation among them.
\end{tabular}

\section{INTRODUCTION}

Human beings are created alongside language to serve as a tool for their daily commination in different spheres of life. Hence, Oxford Advanced Learners' Dictionary 7th Edition defines language as "the system of communication in speech and writing that is used by people of a particular country or area". Language is a system of conventional signals used for communication by a whole community. Further, it seen as the expression of human ideas by means of which sounds are combined into words and words combined into sentences which give birth to ideas and thoughts (Christie, 2002). Block (2003) reveals that language is an extraordinary gift of God. It is part of what makes man fully human.

In Nigeria today, one can view clearly the features of our daily lives especially with regards to the variations that exist in the role of men and women. The reason behind this is that some chauvinists ascribe certain functions to men and women in a particular manner, profession, hobby, social life and norm etc. are sometimes classified according to gender to see women as taxi drivers, motor mechanics, electronic engineers or men as cooks, nurses, many alike some feeling of surprise or outright condemnation. A society with such level of 
gender consciousness must have some of it reflected in its use of language. This is irrespective of whether the language is the mother tongue, or even second to its users. Universally, there is an apparent portrayal of speech pattern of men and women. Most explanations offered for this variations centre on men and women. According to Bjarnegård (2013). "various studies conducted to the consensus that the dominance of the consensus is the dominance of men in conservation, is a reflection of their dominance in the real political world".

\section{LITERATURE REVIEW}

Thus, sociolinguistics has established the variations that exist between the male and female (Strand, 1999; Yassin, \& Razak, 2018). These differences are as a result of the variations that exist in the role expectation, personalities and social perception of people. Even in indigenous Nigerian languages for example, a lot of gender based variations and meaning extension exist in the content, style and characteristics pattern of the languages.

Nigeria is a linguistically heterogonous country with more than five hundred (500) languages spoken (Ogunmodimu 2015). In some Northern Hausa States, meaning extension in communication among youths is noticed visibly to the extent that someone may not even comprehend them when communicating. The research is aimed at point out the meaning extension emanating from gender based communication process in English and Hausa languages, specifically; the study describes the issue of language and gender with particular reference to the mixture of English and Hausa languages used as a form of expression by the youths in some Northern Hausa States.

The primary significance of the study is to close the linguistic gap created as a result of meaning extension in communication and interaction arising from gender based variations among youths (male).

Moreover, the study is expected to assist with its findings in the formulation of language universal in the description of language and gender. Writers in the area might be informed about the problem being encountered in the appreciation of gender based variations in Hausa and English speeches.

Finally, the paper will answer the following questions:

i. Do the expressions make meaning?

ii. To what extent do they use such expressions?

iii. Why do they use these expressions?

\section{METHODOLOGY}

The whole data of the research collected are expressions formed in phrases and sentences used among youths in some Hausa Northern states. The data were analyzed and answers to the research questions were answered accurately. The instrument in the data collection for this research is observation. Observations were made from the male youths of some Northern states in Nigeria such as Katsina, Kano, Kaduna and Zamfara. The data is going to be presented in a form of words, phrases and sentences in order for the research to make the results accurate and reliable. The data will be analysed and break-down according to their factual and contextual meaning.

Analysis of English language data

The analysis is based on the descriptive method in which words would be used to analyse the data. 


\section{Normal}

The above word is an English word used in some Northern States as a form of expression and slogan. The word is defined in the Oxford Advanced Learner's Dictionary 7th Edition as usual or average state, level or standard: above/below normal * Things soon returned to normal*

Quite/perfectly (= completely) normal *Her temperature is normal* It's normal to feel tired after such a long trip*

In some Northern States the word 'normal' is used to answer greetings affirmatively such as 'I'm fine', 'I'm okay' or 'everything is fine'.

\section{Example}

Speaker A: How was your night yesterday?

Speaker B: Normx.

In the above example, speaker A asked speaker B 'how was your night yesterday'? Speaker B replied 'normx' meaning 'it was fine'.

\section{Guarantee}

This word is used in some Northern states. The word in the dictionary refers to Assurance: to give a guarantee of a good behavior. ${ }^{*}$ He gave me a guarantee that it will never happen again* The word is used by the youths in some Northern states to express how certain one is about something or absolutely yes.

\section{Example}

Speaker A: Have you passed your English test?

Speaker B: Guarantee.

In the above example, speaker A asked speaker B 'if he has passed his English test'. Then speaker B replied 'guarantee' meaning yes, he has passed the English test.

\section{Chilling}

The word chilling is oxford dictionary means frightening. The word is said to friends or people that one is very comfortable with. It's used by the youths in some Northern States as relaxing or someone who is living a comfortable life, adopting slang meaning.

\section{Example}

Speaker A: Abokina kana chilling fa.

Speaker B: Hmm.

In the above example, speaker A says in Hausa language 'abokina kana chilling fa' meaning 'my friend you are living comfortably' and speaker B replied ' $\mathrm{hmm}$ '. 


\section{Steady}

The word steady is defined in the Advanced Learners dictionary as developing, growing, etc. gradually and in an even and regular way. Constant: five years of steady economic growth *we are making slow but steady progress. The word steady is used by the youths in some Northern States as 'fine' (to answer greetings).

\section{Example}

Speaker A: How are you?

Speaker B: Steady.

In the above example, speaker A asked speaker B 'how are you'? Then speaker B replied 'steady' meaning he is fine.

\section{Casting}

The word casting has different types of definition in the dictionary, the definitions are:

1. The act or process of making casts or molds.

2. The act of throwing a fishing line or net.

3. Often castings a piece of excrement produced by an earthworm.

4. The selection of actors or performers for the parts of a presentation.

However, in some Northern Hausa States, casting refers to disgrace or embarrassment.

\section{Example}

Speaker A: Are you still using this old computer?

Speaker B: Kada kayi casting dina cikin jama'a.

In the above example, speaker A asked speaker B 'if he was still using that old computer'. Then speaker B replied in Hausa 'kada kayi casting dina cikin jama'a' meaning 'please don't disgrace me in public'.

\section{Analysis of Hausa language data}

\section{Mu Kama}

The above phrase 'Mu Kama' is a Hausa language and a form of expression used among the youths. It literally means 'let's catch' in English. For instance, 'mu kama yaron' meaning 'let's catch the boy'. The expression is used by the youths especially from the Hausa Northern states. Its contextual meaning in this aspect simply refers to 'until we see'. For example, 'mu kama gobe' meaning 'until we see tomorrow'.

\section{Example}

Speaker A: Where are you heading to?

Speaker B: I'm heading home.

Speaker A: Mu kama gobe.

Speaker B: Okay. 
In the above example, speaker A asked speaker B "where are you heading to"? Then speaker B replied "I'm heading home" and speaker A says "mu kama gobe" meaning 'until we see tomorrow' then speaker B replied 'okay'.

\section{Aha}

This form of expression has three contextual meaning. It is used by the youths in some Northern States as a form of slogan in terms of expression in order to hail somebody or to notify someone that you have recognised his presence. In other ways, it means 'Okay'. For instance, someone might see a friend passing by and say 'Aha Musa', it shows that the individual has recognized Musa's presence, then greetings will start between the two individuals. Or, one might say 'help me with the book on the table' then the one who is referred to will reply 'Aha' meaning 'Okay'.

More so, it is used to end a conversation, when two individuals are making a conversation 'Aha' is used in order to show that the conversation has come to an end.

\section{Contextual meanings}

- 'Aha' (to hail someone)

- 'Aha' (okay)

8. Ta goben

- 'Aha' (end a conversation)

The above phrase is a slogan used by the youths in some Northern States. Its contextual meaning refers to 'until we see tomorrow'. While literally means, that of tomorrow.

\section{Contextual meaning}

'Ta goben' (until we see tomorrow)

\section{Shiru ne}

The above phrase in Hausa language literally means 'it's quite'. It is a slogan used by the youths in some Northern States. Its contextual meaning in this aspect means 'nothing from me' or 'nothing for now'.

\section{Example}

Speaker A: Do you have any update about the new minimum wage?

Speaker B: Shiru ne.

In the above example, speaker A asked speaker B about an update of the new minimum wage and speaker B response was 'shiru ne' meaning he has no update about it.

\section{Lafiya lau}

The above phrase is a Hausa language generally used in all the Hausa Northern States as a form of greetings, meaning 'I am fine'.

\section{Example}

Speaker A: How are you? 
Speaker B: Lafiya lau

In the above example, speaker A asked speaker B "How are you"? And speaker B replied "Lafiya lau" meaning 'I am fine'.

More so, in Katsina State 'Lafiya lau' has two meanings, it's used as 'I am fine' and 'all is well', that is positive response.

\section{Example}

Speaker A: Is your pen still working?

Speaker B: Lafiya lau

In the above example, speaker A asked speaker B "is your pen still working"? Then speaker B answered with a positive response and said "Lafiya lau" meaning 'the pen is working'

\section{Ka huta}

The above phrase is a slogan used by the youths in some Northern States. In Hausa language it literally means 'Enjoy yourself'. One can merely see a friend coincidently and say ' $\mathrm{ka}$ huta' meaning 'Enjoy yourself'. It has same meaning both in its literal and contextual meaning. But sometimes, it serves as an imperative statement to someone, meaning 'to rest' after fatigue from tedious work.

\section{Shege ne}

The above phrase literally means 'He's a bastard' in Hausa language, but it contextual meaning in this aspect used to show the level of competence of an individual based on what he does.

\section{Example}

Speaker A: What did you score in Grammar test?

Speaker B: I scored 5/10.

Speaker B: What about you?

Speaker A: I scored 10/10.

Speaker B: Ai kai shege ne.

Speaker A: Hah!.

In the above example, speaker A asked speaker B of his score in Grammar test and speaker B replied "I scored 5/10 and speaker B asked speaker A "what about you"? Then speaker A replied "I scored 10/10" then speaker B said "Ai kai Shege ne" meaning 'you are a brilliant someone' and speaker A replied 'Hah'

\section{Akwai labari wurin ka?}

The above interrogative sentence used as a form of asking question among the youths. It literally means 'Is there any news from you'? But it contextual meaning refers to 'do you have some money with you'? 


\section{Example}

Speaker A: Akwai labari wurin ka?

Speaker B: No.

In the above example, speaker A asked speaker B 'Akwai labari wurin ka'? Meaning 'Do you have some money with you'? Then speaker B replied 'No'.

\section{A star ne}

This form of sentence used as form of expression in a mixture of Hausa and English language at sentence level used by the youths in order to make a complement about a person, thing, object or place.

\section{Example:}

Speaker A: Where did you buy your wrist watch?

Speaker B: I bought it in Dubai.

Speaker A: Agogon a star ne gaskiya.

Speaker B: Thank you.

In the above example, speaker A asked speaker B 'where he bought his watch, and speaker B replied 'I bought it in Dubai' then speaker A replied "gaskiya agogon a star ne" meaning 'honestly, the watch is fabulous' and speaker B said "thank you".

The combination of the words beautifies the sentence in which the ' $a$ ' is a Hausa word (preposition) and 'ne' means focus marker, masculine and it gives a confirmation of something while star is the only English word.

\section{Hantsi}

This word is a form of slogan used by the youths in some Northern States especially in the universities and other tertiary institutions. It contextual meaning in this context is 'Carry over' (an outstanding course which a student failed and has to reseat for it). While literal meaning means ' late morning' or 'forenoon'.

\section{Kaji dadin ka}

The above sentence used as a form of expression is a slogan used by the youths it is used when two individuals meet each other coincidently, then one will unhesitatingly says 'kaji dadin ka' meaning 'make yourself comfortable'. It's usually used among the youths as a byword.

\section{Dan zare}

The above phrase is used in some Northern Hausa States and it contextual meaning means 'a liar' or 'someone who is not specific' but its literal meaning in Hausa means small piece of thread. 


\section{Ba case}

The above phrase is a mix of language at words level that forms an expression used by the youths in a conversation and it's used in some Northern Hausa States. It contextual meaning means 'no problem', it also implies a positive response. Ba in Hausa, means 'No'.

\section{Example}

Speaker A: Can I call you later?

Speaker B: Okay, ba case.

In the above example, speaker A asked speaker B "can I call you later"? Then speaker B replied "okay, ba case”. Meaning 'okay, it's alright'.

\section{Faka-Faka}

The above phrase or alliteration is a form of expression refers to 'quickly' technically. While in Hausa language is sound at a starting point for a bird to fly when moving the wings.

\section{Example}

Speaker A: Can you accompany me to the market?

Speaker B: Yes, let me alight my sister at home.

Speaker A: faka-faka dan Allah.

In the above example, speaker A asked speaker B to accompany him to the market place, then speaker B response was "yes, let me alight my sister at home", and speaker A said "faka-faka dan Allah" meaning 'please make it snappy'.

\section{Kana ruwa}

The above sentence is a form of expression which literally means 'You are in water', but contextually refers to 'You are in danger'.

\section{Example}

Speaker A: where are you transferred to?

Speaker B: I am transferred to Maiduguri.

Speaker A: hah, kana ruwa.

In the above example, speaker A asked speaker B where was he transferred to, then speaker B replied "I am transferred to Maiduguri" and speaker A said "kana ruwa" meaning 'you are in danger'.

\section{Langu}

The above expression is a coinage by the youths; it refers to a very nice voice.

Example: 
Speaker A: I saw Binta talking to our class representative today.

Speaker B: Oh, really

Speaker A: Of course, gaskiya yarinyar akwai langu.

Speaker B: Hmm.

In the above example, speaker A said to speaker B "I saw Binta talking to our class rep. today", then speaker B respond was "oh, really"? Then speaker A said "of course, gaskiya yarinyar akwai langu" meaning 'honestly, the girl has a very nice voice' and speaker B replied "hmm".

\section{Ka ci kai}

The above form of expression has two meaning, it contextually refers to 'You are not well' or 'You are overly drunk'. It also has two usages, it's either used as 'Ka ci kai' or 'Ya ci kai' meaning 'He's overly drunk'.

\section{Example 1:}

Speaker A: Can you drive a car while eating?

Speaker B: Gaskiya ka ci kai.

In the above example, speaker A asked speaker B if he could drive a car while eating, then speaker B replied 'gaskiya ka ci kai' meaning 'honestly, you're not well'.

\section{Example 2:}

Speaker A: Is that old man holding a bottle talking to himself?

Speaker B: Yes, I think so.

Speaker A: Ya ci kai.

In the afore-mentioned example, speaker A asked speaker B "is that old man holding a bottle talking to himself"? Then speaker B replied "yes, I think so" and speaker A said "ya ci kai" meaning 'he's overly drunk'.

\section{Kayi komai ba komai}

The above sentence refers to a privileged someone. It is said when two individuals meet together, or when somebody is walking around and see his colleague then he will say 'kaji dadin ka' meaning 'you're privileged to do whatever you wish'.

\section{Sa ta}

The above expression refers to 'run away' contextually while literally means 'put it'.

\section{Example}

Speaker A: Are those soldiers coming to my direction?

Speaker B: Yes, they are. 
Speaker B: Ka sa ta kawai.

In the above example, speaker A asked speaker B "were those soldiers coming to his direction"? Then speaker B replied "yes, they are" "ka sa ta kawai" meaning "just run away".

\section{Ina ganin rayuwa}

The above sentence means 'I'm facing hard times' and it contextual meaning refers to

'I'm financially broke'.

\section{Example}

Speaker A: Do you have some money with you?

Speaker B: A'a, ina ganin rayuwa ne.

In the above example, speaker A asked speaker B if he had some money with him, then speaker B replied "No, ina ganin rayuwa" meaning 'No, I'm financially broke'.

\section{RESULT AND DISCUSSION}

Based on the presentation and analysis of the data gathered in the previous section, the analysis confirms the expression meanings and its usages with numerous examples used by the youths in some northern States.

More so, some of the data are less regarded as an expression but a form of slogan and bywords used for expression among the youths in some Northern States. In the discussion, the research questions have been answered below:

\section{Do the expressions make meaning?}

This is answered respectively in the previous analysis because all the expressions were analyzed based on their literal and contextual meanings. When looking critically at the expressions, one will see how each of the expression in a form of conversation makes meaning and if the message is really understood between two participants or parties, therefore, communication took place. And for that reason, the expressions of course make meaning. In addition, all the expressions, sentence and words have meaning extension which is only understood among the youths.

\section{To what extent do they use such expressions?}

The second research question proves that, this form of expressions used by youths in some northern part of the country aren't always, but rather once in a while because they are only forms of expression they used to express something different from its literal meaning, similar to the English idioms. In a nutshell, the usage is casual.

3. Why do they use these expressions?

The third research question also shows that some youths used these expressions for them to communicate among themselves using a lingo that only them can understand and one who is unfamiliar with the expressions will never get the message clearly, rather he misinterprets the whole text or message. And they used these kinds of expressions normally in an informal setting like: talking to a friend, family, chatting etc. Meanwhile, they use the expressions in order to fancy or impress, or as a sign of wiseness.

Based on the analysis and results, the following are the research findings as follows: 
1. The expressions are strictly used among the youths of some northern States, both the educated and uneducated (western education) ones.

2. The form of expressions conveys meaning which is totally different from its literal meaning.

3. That, the expressions are not used frequently but rather in a casual and informal setting.

4. They also serve as a symbol of wiseness among the youths that is someone is in a particular range of age or high level.

\section{CONCLUSION}

The paper has done a comprehensive observation and gave a clear account on the usage of language in the social setting of some youths in some northern states in trying to create an avenue that can serve as a medium of communication among themselves. And it showed the level in which the youth went ahead to manipulate the language in extending the meaning purposely for their communication among their peers. In conclusion, the paper portrayed how they use the language not very often for fancy and esteem.

\section{REFERENCE}

Bjarnegård, E. (2013). Gender, Informal Institutions and Political Recruitment: Explaining Male Dominance in Parliamentary Representation. Springer.

Block, D., (2003): The Social Turn in Second Language Acquisition. Edinburgh: Edinburgh University Press.

Christie, F. (2002): Language and Classroom Discourse Analysis: A functional perspective. London Continuum.

Ogunmodimu, M. (2015). Language Policy in Nigeria: Problems, Prospects and Perspectives. International Journal of Humanities and Social Science, 5(9), 154-160.

Oxford Advanced Learners' Dictionary $7^{\text {th }}$ Edition.

Strand, E. A. (1999). Uncovering the Role of Gender Stereotypes in Speech Perception. Journal of Language and Social Psychology, 18(1), 86-100.

Yassin, A. A., \& Razak, N. A. (2018). Request Strategies: A Contrastive Study Between Yemeni EFL and Malay ESL Secondary School Students in Malaysia. Asian Social Science, 14(12).

\section{$\underline{\text { AUTHORS' BIOS }}$}

Bello Ibrahim, holds his BA English from Al-Qalam University, Katsina and MA in English Language with thesis in Applied Linguistics from Bayero University, Kano all in Nigeria. I started lecturing in the department of English, Al-Qalam University, Katsina in 2012 to date. I taught many language and literature courses such as Applied Linguistics, Semantics, Grammar, Intro to Literature, Poetry etc. I also published many articles national and international ones. 
Lirwan Yusuf is a graduating student of the department of English, Al-Qalam University, Katsina.

Hamisu Hamisu Haruna has BA Ed. English, MA English Language from Bayero University, Kano. He joined the department of English Al-Qalam University, Katsina as a lecturer in 2015 and taught language and literature courses. He also has articles published and presented nationally and internationally. 